\title{
OCORRÊNCIA DE SUSPEITAS DE ZOOFILIA NO ATENDIMENTO CLÍNICO MÉDICO-VETERINÁRIO EM MARÍLIA/SP NO PERÍODO DE 2018-2019: maus-tratos velado e negligenciado
}

\author{
Occurrence of suspected zoophilia in veterinary clinical care in \\ Marilia/SP in 2018-2019: veiled and neglected animal abuse
}

\author{
Elma Pereira dos Santos Polegato ${ }^{1}$, Isabela Baroni Teixeira² ${ }^{2}$ Mariana Vieira Angeli², \\ Jéssica Pesqueira Paié2. \\ *Autor Correspondente: Elma Pereira dos Santos Polegato. Av. Hygino M. Filho, \\ 1001, Marília, SP. CEP: 17525-902. \\ E-mail: elmapolegato@hotmail.com
}

\begin{abstract}
Como citar: POLEGATO, E. P. S. et al. Ocorrência de suspeitas de zoofilia no atendimento clínico médicoveterinário em Marília/SP no período de 2018-2019: maus-tratos velado e negligenciado. Revista de Educação Continuada em Medicina Veterinária e Zootecnia do CRMV-SP, São Paulo, v. 19, n. 1, 2021. DOl: https://doi.org/10.36440/recmvz.v19i1.38251.

Cite as: POLEGATO, E. P. S. et al. Occurrence of suspected zoophilia in veterinary clinical care in Marilia/SP in 2018-2019: veiled and neglected animal abuse. Journal of Continuing Education in Veterinary Medicine and Animal Science of CRMV-SP, São Paulo, v. 19, n. 1, 2021. DOl: https://doi.org/10.36440/recmvz. v19i1.38251.
\end{abstract}

\section{Resumo}

O relacionamento entre homens e animais é uma entidade complexa iniciada com a domesticação dos animais e mantida até hoje graças aos efeitos positivos na saúde e comportamento humanos. A melhora psicológica e emocional das pessoas que convivem com animais de estimação, têm sido associada à melhoria na qualidade de vida e ao convívio social em geral. Porém, esse relacionamento nem sempre foi ético e ambientalmente correto, pois no cotidiano observam-se arbitrariedades praticadas pelo homem que aniquilam a dignidade dos animais, geralmente indefesos, promovendo todas as modalidades de abusos, maus-tratos e crueldade. 0 Brasil possui leis de amparo aos crimes praticados contra abuso e maus-tratos aos animais e dentre os vários tipos de maus-tratos existe a zoofilia ou bestialismo, prática do ato sexual pelo ser humano com animais de outras espécies. 0 presente trabalho levantou dados na prática clínica médico-veterinária em Marília (SP) quanto ao atendimento de casos suspeitos de zoofilia e discute aspectos psicológicos, culturais sobre a legislação que trata do tema. A metodologia adotada foi a

\footnotetext{
1 Docente, Faculdade de Ciências Agrárias, Disciplina de Ética, Bioética e Legislação Profissional, Marília, SP, Brasil

2 Discente, Universidade de Marília (Unimar), Faculdade de Ciências Agrárias, Disciplina de Ética, Bioética e Legislação Profissional, Marília, SP, Brasil
} 
aplicação de um questionário com questões abertas e de múltipla escolha a clínicos médicos-veterinários em atividade no município de Marília, estado de São Paulo, Brasil, e a revisão do assunto nos últimos cinco anos. A análise das informações obtidas com 50 médicos-veterinários, no período de setembro de 2018 a março de 2019, apresentou 54\% de relatos de atendimento com suspeita de zoofilia com maior frequência em fêmeas, incluindo cães, equinos, pequenos ruminantes e ruminantes. Finalmente, é discutida a importância social do estabelecimento de um tipo penal específico para a bestialidade como 0 primeiro passo para construção de uma sociedade mais justa e menos maléfica e violenta, destacando-se também que as pessoas que praticam zoofilia necessitam ser devidamente tratadas por um profissional competente, pois essa prática é um grave problema psicológico.

Palavras-chave: Zoofilia. Bestialidade. Abuso. Maus-tratos. Legislação.

\section{Abstract}

The relationship between men and animals is a complex entity initiated with the domestication of animals and maintained until today that promotes positive effects on human health and behavior. It was demonstrated the psychological and emotional improvement of people due to living with pets, and also an improvement in their quality of life and social interaction in general. However, this relationship has not always been ethical and environmentally correct, since human can also promote all forms of abuse, mistreatment and cruelty to them that are defenseless. In Brazil there are laws for punishment of abuse and mistreatment of animals and among the various types of mistreatment there is zoophilia or bestiality which is the sexual act of humans with animals of other species. From September 2018 to March 2019 it was applied a questionnaire with open questions and multiple choices to 50 veterinary clinicians working in Marília, São Paulo State, Brazil, regarding the suspicion of cases of zoophilia, and it was also discussed the psychological, cultural aspects and specific legislation about this matter. The results obtained showed that 27 (54\%) of the veterinarians reported the suspicion of zoophilia with more occurrence in females than males, and the most affected species were dogs, horses, small ruminants and ruminants. Finally, it was performed a discussion showing that the settlement of a specific legislation criminalizing zoophilia it is necessary to build a fairer and less harmful and violent society, and that the people who practice it must be properly treated by a competent professional, as it is also an indication of psychological problems.

Keywords: Zoophilia. Bestiality. Animal Abuse. Legislation.

\section{Introdução}

0 relacionamento entre homens e animais é uma entidade complexa iniciada nos primórdios da história da humanidade com a domesticação dos animais e que é mantida até hoje graças aos efeitos positivos na saúde e comportamento humano (ALMEIDA; ALMEIDA; BRAGA, 2009). No Brasil, estimativas populacionais indicaram a existência de 132 milhões de animais de estimação entre cães e gatos, ou seja, há mais cães e gatos nos lares brasileiros do que crianças, elevando-se assim o status desses animais como membros das famílias (IBGE, 2013).

Almeida, Almeida e Braga (2009) destacaram que as pessoas que convivem com animais de estimação apresentam níveis de estresse e de pressão arterial controlados, e que têm menor chance de desenvolver problemas cardíacos. De fato, a melhora psicológica e emocional do convívio homem e animal de estimação têm sido confirmadas, pois os tutores de cães e gatos afirmam que as suas qualidades de vida melhoraram após a introdução dos animais de estimação nos seus lares, sendo observada também uma diminuição das tensões entre os membros da família e melhoria geral no convívio social. Destaque-se, contudo, que, na atualidade, há muitas arbitrariedades praticadas pelo homem que aniquilam a dignidade dos animais, geralmente indefesos, e que são submetidos a muitas modalidades de abusos, maus-tratos e crueldade, ou então, são adestrados para se tornarem violentos e, assim, portá-los como se fossem armas, quando não os abandonam a toda sorte de riscos, 
transformando-os em vítimas inocentes e agentes de doenças, afetando, inclusive, a saúde pública, demonstrando que o relacionamento entre humanos e animais de estimação nem sempre é ético e ambientalmente correto (SANTANA; OLIVEIRA, 2004).

A Declaração Universal dos Direitos dos Animais da Unesco (1978, p. 1), celebrada na Bélgica e subscrita pelo Brasil, elenca entre os direitos dos animais o de "não ser submetido a sofrimentos físicos ou comportamentos antinaturais". Nesse sentido, a humanidade tem se sensibilizado com ações que importem em maus-tratos e crueldade contra os animais, procurando, em diversas partes do mundo, promulgar e implementar normas que garantam o respeito à vida, ao bem-estar e à dignidade destes seres vivos, proibindo atos que lhes imponham sofrimentos desnecessários (SANTANA; MARQUES, 2010).

De acordo com o artigo 32 da Lei no 9.605 de 12 de fevereiro de 1998 (BRASIL, 1998, p. 6), “[...] praticar ato de abuso, maus-tratos, ferir ou mutilar animais silvestres, domésticos ou domesticados, nativos ou exóticos confere ao réu pena de detenção de três meses a um ano", porém, no Brasil, na maioria das vezes, este crime é subnotificado, pois a sua investigação depende de provas, especialmente da prova pericial médico-veterinária legal, que é dificultada pela baixa disponibilidade de profissionais e de órgãos especializados trabalhando em sintonia com a Polícia Judiciária (DELABARY, 2012; MARLET; MAIORKA, 2010).

Dentre os diversos tipos de maus-tratos praticados contra os animais, a zoofilia é a prática do ato sexual por ser humano com animais de outras espécies quando há o contato dos órgãos sexuais, com ou sem penetração. Oliveira (2013) descreveu que a masturbação das genitálias dos animais, sexo oral, anal, vaginal entre homem ou mulher com o animal, macho ou fêmea, é entendida como uma prática zoófila. Também há o termo bestialismo, cuja definição pelo Dicionário Priberam da Língua Portuguesa (2008-2020, p.) é "[Psicopatologia] Prática sexual com animais = bestialidade, zooerastia".

Portanto, zoofilia, também conhecida historicamente por bestialidade, consiste na prática sexual de humanos com animais, treinados ou não, para fins de excitação, masturbação, contato oral-genital ou penetração (PRÓTON, 2017).

A despeito de existirem várias denominações para a prática de relações sexuais entre humanos e animais, na atualidade, nas áreas médicas e jurídicas prevalecem os termos zoofilia e bestialidade, às vezes, utilizados como sinônimos, porém possuem abordagens e condutas jurídicas distintas, pois, ao praticante de bestialismo deve ser imputado o crime de maus-tratos aos animais, ao passo que para o praticante de zoofilia, uma patologia, deve ser comprovado que o praticante de tais atos é portador de desordens mentais classificadas no Manual Diagnóstico e Estatístico de Transtornos Mentais - DSM-5 (LUCENA; ABDO, 2014), onde a zoofilia é considerada um "transtorno parafílico não especificado" e não uma perversão. Assim, a caracterização da zoofilia ou bestialismo deve ser firmada por um profissional competente, porém, nos dois casos há abuso e sofrimento aos animais que precisam ser combatidos.

Bizawu e Ramos (2017) ressaltam que a zoofilia pode estar associada a outros distúrbios de origem sexual ou até mesmo a violência e que pessoas praticantes de "bestialismo" tendem à prática de crimes mais graves, inclusive contra crianças, por ser inerente a eles o prazer da dominação.

Fleming, Jory e Burton (2002) observaram que $96 \%$ dos jovens que tiveram relações sexuais com animais não humanos, também admitiram ter cometido crimes sexuais contra humanos e relataram vários outros delitos, como roubo, estupro e abandono. Portanto, isso pode ser um forte indício de que a prática do sexo com animais apresente um elo com a violência humana com possibilidade, dentre outras ocorrências, de crimes sexuais contra crianças, mulheres e seres humanos em geral.

Bizawu e Ramos (2017) ressaltam, ainda, que a prática da zoofilia pode estar associada à transmissão de doenças como, por exemplo, o câncer e as doenças sexualmente transmissíveis.

Zequi (2011) investigou 492 homens que viviam em zonas rurais brasileiras, dos quais 118 apresentavam câncer de pênis e 374 eram sadios e identificou que quase quatro entre 10 pessoas que 
vivem nestas regiões tiveram uma ou mais relações com animais, e que essa prática dobrava o risco de desenvolvimento do câncer de pênis. A despeito desta prática ser vista com certa normalidade, a CID10 (Classificação Internacional de Doenças) seja F65.8 (Outros Transtornos de Ordem Sexual) considera a zoofilia como uma doença de caráter psicológico.

Oliveira (2013) descreveu que a prática sexual com animais também é realizada por mulheres principalmente para o cinema pornográfico, no qual há predomínio da produção de filmes com relação sexual de animais machos com mulheres, porém voltado para atender ao interesse de um público predominantemente masculino.

O presente trabalho levantou dados com clínicos médico-veterinários que atuam em Marília(SP) quanto ao atendimento de casos suspeitos de zoofilia e discute aspectos psicológicos, culturais sobre a legislação brasileira e de outros países sobre o tema.

\section{Material e método}

O projeto de pesquisa foi submetido à apreciação da Comissão Nacional de Ética em Pesquisa CONEP com CAAE n. 04751018.1.0000.5496 e parecer favorável n. 3137113.

0 instrumento metodológico utilizado para a realização da pesquisa foi a aplicação de questionário contendo 5 (cinco) questões, 3 (três) delas abertas com espaço para considerações sobre o tema e 2 (duas) de múltipla escolha, feitas a 50 (cinquenta) médicos-veterinários responsáveis técnicos por 50 (cinquenta) estabelecimentos de saúde animal com licença de funcionamento na Vigilância Sanitária de Marília (SP), no período de setembro de 2018 a março de 2019. A abordagem aos profissionais foi realizada por integrantes do grupo de pesquisa, portando o Termo de Consentimento Livre e Esclarecido (TCLE), assinado quando da concordância em participar da pesquisa e carta-convite com as questões que registraram informações sobre: (1) tempo de atendimento clínico-médico-veterinário (experiência profissional); (2) se já atendeu animais, cuja suspeita tenha sido ou poderia ser zoofilia; (3) Relatar a proporção de casos suspeitos ou confirmados num bloco de diversos atendimentos; (4) Quais são as principais espécies e sexo mais acometidos; (5) Considerações e comentários relevantes. As respostas foram entregues, posteriormente, conforme acordado entre as partes. Como critérios de inclusão foi entrevistado 1 (um) médico-veterinário por estabelecimento, de preferência o responsável técnico principal ou, na sua ausência, o primeiro substituto, de forma que todos os estabelecimentos com licença de funcionamento na Vigilância Sanitária de Marília (SP) fossem contemplados.

\section{Resultados e Discussão}

Marília, estado de São Paulo, Brasil, em setembro de 2018, possuía 50 (cinquenta) estabelecimentos médico-veterinários que prestavam serviços em saúde animal como consultórios, clínicas e hospitais veterinários com licença de funcionamento na Vigilância Sanitária do município. Dos 50 (cinquenta) médicos-veterinários entrevistados, 27 (vinte e sete) relataram já terem realizado atendimento clínico em que houve a suspeita de zoofilia (Tabela 1). 
Tabela 1 - Distribuição das respostas dos médicos-veterinários entrevistados quanto ao atendimento de casos suspeitos de zoofilia e quanto a opinião de qual sexo é mais acometido por zoofilia em Marília (SP), entre 2018-2019

\begin{tabular}{|l|l|}
\hline \multicolumn{1}{|c|}{ Entrevistados $(\%)$} & Opinião quanto ao sexo mais acometido (\%) \\
\hline Atenderam casos suspeitos $=27(54 \%)$ & Fêmeas $=30(60 \%)$ \\
\hline Não atenderam casos suspeitos $=23(46 \%)$ & Machos $=02(4 \%)$ \\
\hline Total = 50 (100\%) & Ambos $=18(36 \%)$ \\
\hline
\end{tabular}

T Fonte: Os autores (2019).

Com relação ao sexo dos animais mais acometidos, 30 dos profissionais entrevistados descreveram que somente fêmeas são acometidas, 18 relataram que ambos os sexos e apenas 2 médicos-veterinários discorreram que somente machos sofrem esta violência, conforme demonstrado na Tabela 1. As espécies mais acometidas foram cães, pequenos ruminantes, equinos, asininos e muares, ruminantes e galinhas, não havendo acometimento de felinos, conforme apresentado na Figura 1.

Figura 1 - Distribuição das espécies mais acometidas por suspeita de zoofilia na opinião dos entrevistados em Marília-SP, em 2018-2019, considerando que a resposta individual pode conter mais de uma espécie no questionário proposto

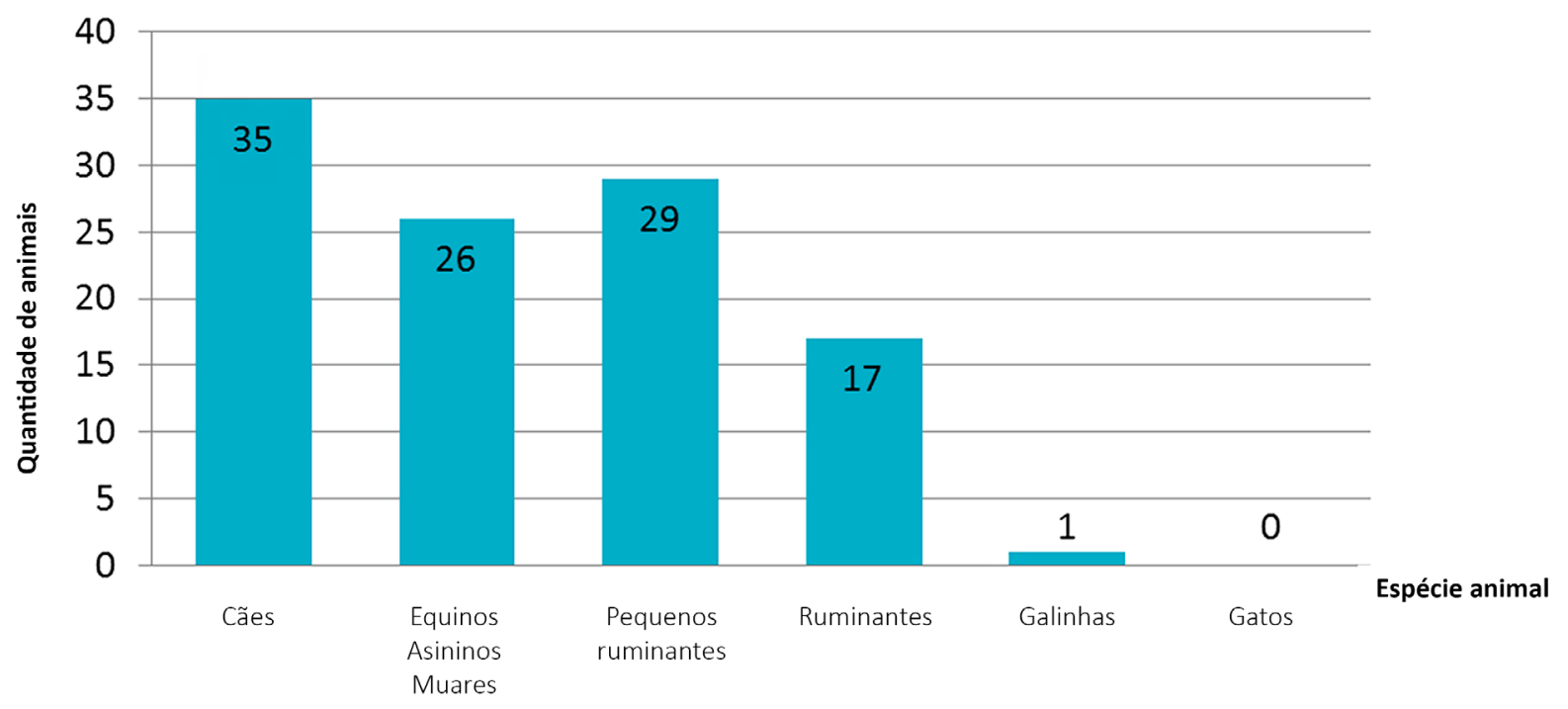

TFonte: Os autores (2019).

Considerando uma proporção de ocorrência de suspeita de zoofilia num bloco de diversos atendimentos, os 27 profissionais, que já atenderam animais cuja suspeita tenha sido zoofilia, assinalaram a proporção de ocorrência de 1 (um) caso a cada 1.000 atendimentos clínicos realizados. Essa baixa ocorrência mencionada aliada a falta de orientação de como proceder pode justificar a inexistência de uma conduta profissional que motive a denúncia de tais ocorrências. Outro fator que também pode explicar a baixa ocorrência é que os animais que sofreram o abuso não são encaminhados para atendimento médico-veterinário. 
As respostas das perguntas que tratavam do tempo de atuação e experiência dos profissionais questionados são apresentadas na Tabela 2. Dezoito profissionais (36\%) tinham até 5 anos de experiência em atendimento clínico e 32 (64\%) possuíam entre 6 a 25 anos de formação e atuação em clínica veterinária, portanto, com maior experiência para diferenciar lesões e apontar as possíveis causas.

A proporção de ocorrências obtidas nos atendimentos clínicos veterinários, em Marília (SP), quanto a suspeita de zoofilia é rara, com maior frequência de ocorrência em cadelas e pequenos ruminantes em geral (Figura 1 ).

Tabela 2 - Distribuição do número/percentual de médicos-veterinários, entrevistados em Marília (SP), em 2018-2019, de acordo com a experiência profissional (anos) em clínica veterinária

\begin{tabular}{|c|c|}
\hline Experiência profissional & Número de profissionais (\%) \\
\hline $\mathbf{1}$ a $\mathbf{5}$ anos & $18(36 \%)$ \\
\hline $\mathbf{6}$ a $\mathbf{1 0}$ anos & $06(12 \%)$ \\
\hline $\mathbf{1 1}$ a $\mathbf{1 5}$ anos & $09(18 \%)$ \\
\hline $\mathbf{1 6}$ a $\mathbf{2 0}$ anos & $10(20 \%)$ \\
\hline $\mathbf{2 1}$ a $\mathbf{2 5}$ anos & $05(10 \%)$ \\
\hline Acima de $\mathbf{2 5}$ anos & $02(4,0 \%)$ \\
\hline TOTAL & $50(100 \%)$ \\
\hline
\end{tabular}

TFonte: Os autores (2019).

Alguns médicos-veterinários entrevistados fizeram considerações verbais sobre a zoofilia, dizendo ser um transtorno mental ou psicopatia, negligenciado pela sociedade, e que é necessária uma legislação específica para tratar deste tema no Brasil, incluindo a sua punição. Além disso, alguns se sentiam impotentes e sem respaldo legal para agir.

Normalmente, os médicos-veterinários são confrontados com a questão do contato sexual entre humanos e animais apenas se o animal estiver ferido ou quando apresenta uma infecção e o tutor/proprietário decide levar o animal para um exame. Poucos estudos investigaram a relevância da bestialidade para o campo da Medicina Veterinária, pois, como em outras profissões, esse assunto não é facilmente abordado conforme Beirne (1997), em ensaio intitulado "Repensando a bestialidade", no qual descreve o "curioso silêncio" que cerca o abuso sexual de animais. 0 mesmo autor aponta que embora "todas as sociedades conhecidas provavelmente tenham aplicado alguma forma de censura às relações sexuais entre humanos e animais", o abuso nunca foi censurado com base no dano que inflige aos animais.

Weidner (1972), na Alemanha, questionou 400 (quatrocentos) médicos-veterinários sobre casos de abuso sexual e sádico de animais observados em suas clínicas. Dos 294 (duzentos e noventa e quatro) médicos-veterinários que responderam 106 (36\%) relataram atendimento de animais que sofreram abuso sexual e que os animais tratados com mais frequência eram vacas e bezerros, mas cavalos, porcos, ovelhas, aves e cabras também eram acometidos. Em relação à população por espécie na Alemanha, naquela época, os cavalos eram os mais frequentemente envolvidos. Já Beetz (2005), Miletski (2005), Williams e Weinberg (2003), em pesquisas posteriores também realizadas na Alemanha, identificaram que a espécie canina também era alvo de abordagens sexuais. Essas observações concordam com as informações levantadas no presente trabalho. 
Beetz (2005) relatou que casos de contato sexual com cães, inclusive com penetração, que não resultam em ferimentos, provavelmente não são notados em uma clínica veterinária, mesmo que o cão seja levado lá para exames regulares. No caso de um ato sexual determinar o estabelecimento de lesões no animal, um médico-veterinário, muitas vezes, não será contatado devido ao medo e vergonha do tutor.

No Reino Unido, Munro e Thrusfield (2005), analisando a ocorrência de lesões não acidentais em pequenos animais atendidos em estabelecimentos de saúde animal, identificaram 448 (quatrocentos e quarenta e oito) casos dos quais, 28 (6,25\%) foram de lesões de natureza sexual com 21 (vinte e um) casos em cães, 5 (cinco) em gatos e 2 (dois) em espécies não especificadas. Os motivos para suspeitar de abuso sexual foram: o tipo de lesão; comportamento do proprietário; declarações de testemunhas; e admissão pelo perpetrador. Os tipos de lesão incluíram lesão penetrativa vaginal e anorretal (peniana e não peniana), lesão perianal e trauma nos órgãos genitais. Alguns ferimentos foram graves e alguns foram fatais. Em contraste, outros casos não revelaram danos óbvios.

No Brasil, Bizawu e Ramos (2017) relataram que ocorrências de zoofilia em diferentes localidades do País, tanto em área urbana como rural, foram investigadas pela Polícia Civil, a partir de denúncias de representantes de entidades protetoras de animais e pessoas da sociedade local com acometimento de várias espécies animais como cães, equinos, bovinos e suínos, porém em todos os casos as punições, quando imputadas, foram brandas. Muitas vezes, o criminoso se valia de alegações de insanidade mental e transtorno sexual, sendo liberado e voltando normalmente ao convívio com animais e com outros seres humanos, ficando os animais com o sofrimento físico e psicológico inerentes aos abusos sofridos.

Do ponto de vista médico, há duas classificações para a zoofilia, uma pertinente a psicologia que é denominada perversão, e a outra, relacionada à psiquiatria que classifica a zoofilia internacionalmente, por meio da CID-10, como transtorno mental denominado como parafilia.

De acordo com Lopes (2017, p. 6), há vários grupos de parafilias, estando a zoofilia classificada no "grupo animais", definido como:

Os parafílicos obterão prazer e satisfação sexual por e com animais, algumas das parafilias pertencentes a esse grupo são: a Zoofilia e a Formicofilia que é uma variação da zoofilia e consiste na excitação e obtenção de prazer com pequenos animais, p. e.: rãs, formigas, lagartos e insetos. (LOPES, 2017, p. 6)

Em alguns casos, há uma união de desejo da zoofilia com necrofilia que é o desejo sexual por cadáveres, considerado também um transtorno mental.

Oliveira (2013) descreveu que, a despeito da prática da zoofilia ser mais comum por parte de homens, ela também é praticada por mulheres e que homens realizam sexo com penetração em animais fêmeas ou machos de pequeno e médio porte, como as galinhas, cachorros, cabras ou ovelhas; e as mulheres, por sua vez, podem vir a praticar sexo com animais machos, tais como cães, cavalos e touros.

Independente de quem pratica a zoofilia, seja homem ou mulher, tal ato resulta ou pode resultar em sérios e irreversíveis danos físicos nesses animais, o que envolve, obviamente, dor e sofrimento para eles, pois não possuem estrutura física compatível para atividade sexual com humanos.

Considerando os aspectos legais, no Brasil, embora a zoofilia ainda não possua uma lei específica, a sua abordagem é feita por meio da Lei no 9.605, de fevereiro de 1998, de crimes ambientais que geram sanções penais e administrativas, que podem levar à detenção de três meses a um ano, além de multa. Recentemente, foi criada a Lei Federal no 14.064, de 29 de setembro de 2020, que altera a Lei no 9.605/1998, aumentando as penas cominadas ao crime de maus-tratos aos animais quando se tratar de cão ou gato, cuja pena vai de 2 (dois) a 5 (cinco) anos de reclusão, multa e perda da guarda do animal, porém sem inclusão da zoofilia como crime (BRASIL, 2020). 
Próton (2017) relatou que criminalizar a zoofilia como crime ambiental reafirma o caráter instrumental dos animais, desconsiderando que eles são seres sencientes, pois leva em consideração a função que cumprem no meio ambiente e não as necessidades de um sujeito provido de direitos simplesmente porque tem vida, independentemente de qualquer outra justificativa ou significação.

França, Itália, Estados Unidos, Portugal, Suécia, Turquia, Espanha e Dinamarca possuem legislações específicas tratando da proibição da zoofilia, estando o acusado sujeito a processo civil e punido com multa e/ou prisão (GRAVINATTI; BIONDO; GARCIA, 2015).

Na Alemanha, em 4 de fevereiro de 2013, foi aprovada a lei que incrimina e proíbe a prática da zoofilia, devido ao crescente número de animais que foram torturados ou morreram em razão de abusos sexuais dos quais foram vítimas (BIZAWU; RAMOS, 2017).

Singer (1999) destacou que o ato sexual com animais pode ser considerado como estupro, pois o animal se assemelha a condição de uma mulher ou criança que está sendo coagida a praticar sexo, com ou sem penetração, com ou sem sofrimento, pois não há escolha ou consentimento por parte do animal que está à mercê do abusador.

A prática da zoofilia, além de violência aos animais, tem tomado proporções preocupantes, uma vez que animais vêm sendo estuprados, escravizados e torturados não apenas pela satisfação sexual pessoal do zoófilo, mas também pela existência de um mercado que lucra com essas práticas sexuais contra animais, visando também lucro no agenciamento de animais para prática de programa, filmes, vídeos, e outros meios audiovisuais (BIZAWU; RAMOS, 2017).

Um exemplo de mercado que lucra com o abuso sexual de animais é a existência de bordeis de animais para práticas zoófilas em países como Tailândia, Indonésia e outras localidades na Ásia, onde orangotangos fêmeas são acorrentadas e obrigadas a satisfazer sexualmente turistas e homens da região, submetidas a constante assédio (DARAYA, 2014).

A Medicina Veterinária pelo Sistema CFMV/CRMVs, em cumprimento aos princípios profissionais de denunciar às autoridades competentes qualquer forma de agressão aos animais e ao meio-ambiente e empenhar-se para melhorar as condições de bem-estar, saúde animal, humana, ambiental, e os padrões de serviços médicos-veterinários, publicou em seu portal orientação aos profissionais médicosveterinários e a toda a sociedade quanto aos procedimentos necessários para denunciar os vários tipos de maus-tratos aos animais, conforme demonstrado na Figura 2, sendo que os casos de zoofilia também devem ser contemplados.

Ainda, a Resolução CFMV no 1.236, de 26 de outubro de 2018, regula administrativamente os atos dos médicos-veterinários:

Define e caracteriza crueldade, abuso e maus-tratos contra animais vertebrados, dispõe sobre a conduta de médicos-veterinários e zootecnistas e dá outras providências.

RESOLVE:

Art. 10 Instituir norma reguladora relativa à conduta do médico-veterinário e do zootecnista em relação a constatação de crueldade, abuso e maus-tratos aos animais.

Art. 20 Para os fins desta Resolução devem ser consideradas as seguintes definições:

[...] IV - abuso: qualquer ato intencional, comissivo ou omissivo, que implique no uso despropositado, indevido, excessivo, demasiado, incorreto de animais, causando prejuízos de ordem física e/ou psicológica, incluindo os atos caracterizados como abuso sexual;

$\S 2^{\circ}$ - 0 médico-veterinário deve registrar a constatação ou suspeita de crueldade, abuso ou maus-tratos no prontuário médico, parecer ou relatório, e o zootecnista, em termo de constatação, parecer ou relatório, para se eximir da participação ou omissão em face do ato danoso ao(s) animal(is), indicando responsável, local, data, fatos e situações pormenorizados, 
finalizando com sua assinatura, carimbo e data do documento. Tal documento deve ser remetido imediatamente ao CRMV de sua circunscrição, por qualquer meio físico ou eletrônico, para registro temporal, podendo o CRMV enviar o respectivo documento para as autoridades competentes. (CFMV, 2018, p. 54)

Portanto o Sistema CFMV/CRMVs tipifica os abusos sexuais como maus-tratos e orienta a obrigação do profissional médico-veterinário relatar em detalhes a suspeita de maus-tratos em prontuário, que deve ser enviado ao CRMV para serem tomadas as providências.

A coleta de informações do tutor e a análise do comportamento do animal devem ser os primeiros passos para a identificação de um caso de abuso sexual. Animais de grande porte, como os de produção, podem não apresentar lesões aparentes, porém não devem ser negligenciados na investigação. Animais de pequeno porte ou companhia, geralmente, apresentam lesões evidentes, facilitando a identificação de caso suspeito (GRAVINATTI; BIONDO; GARCIA, 2015).

Gravinatti, Biondo e Garcia (2015) salientam que o diagnóstico de um caso de zoofilia não pode ser baseado apenas no diferencial do sistema reprodutivo, região perianal e anal. Na avaliação devem ser observados os estímulos em esfíncteres (tônus e reação pupilar) em ambos os sexos. As fêmeas podem apresentar trauma vaginal, vaginite recorrente, edema e hiperemia vulvar, hemorragia e/ou prolapso vaginal, fissuras próximo a cérvix (observadas com o emprego de espéculo e otoscópio), uterite (piometra). Os machos podem apresentar necrose de escroto, testículos ou pênis. Quando a prática é relacionada à região perianal e anal podem ser encontrados sinais como necrose da mucosa anal, fissura anal, prolapso retal, dilatação do esfíncter, hematoquezia, tenesmo, peritonite, entre outros.

A formação de base do médico-veterinário para identificar sinais de crimes de zoofilia ou bestialismo, o torna competente para executar prova pericial nestas situações, sendo elemento fundamental para a investigação criminal. Portanto, tem o dever de se manter alerta para sinais de abuso e maus-tratos aos animais.

Próton (2017) ressaltou que ignorar uma prática tão antiga como a zoofilia ou bestialismo não faz com que ela deixe de existir, tampouco afasta a violência, tortura e morte impostas aos animais. A partir do momento que os animais perderem o seu caráter de objetos ou meras propriedades, caberá ao Direito tipificar a conduta bestial como estupro de vulnerável. Questão tão necessária, atual e negligenciada por nossos legisladores.

A tipificação penal da bestialidade como estupro de vulnerável será um resultado do progresso humano, seja do reconhecimento dos animais como sujeitos de direitos e sua senciência, seja de todo o mal imposto aos animais nas práticas sexuais egocêntricas e patológicas. 
Figura 2 - Etapas e órgãos oficiais para a denúncia de maus-tratos aos animais

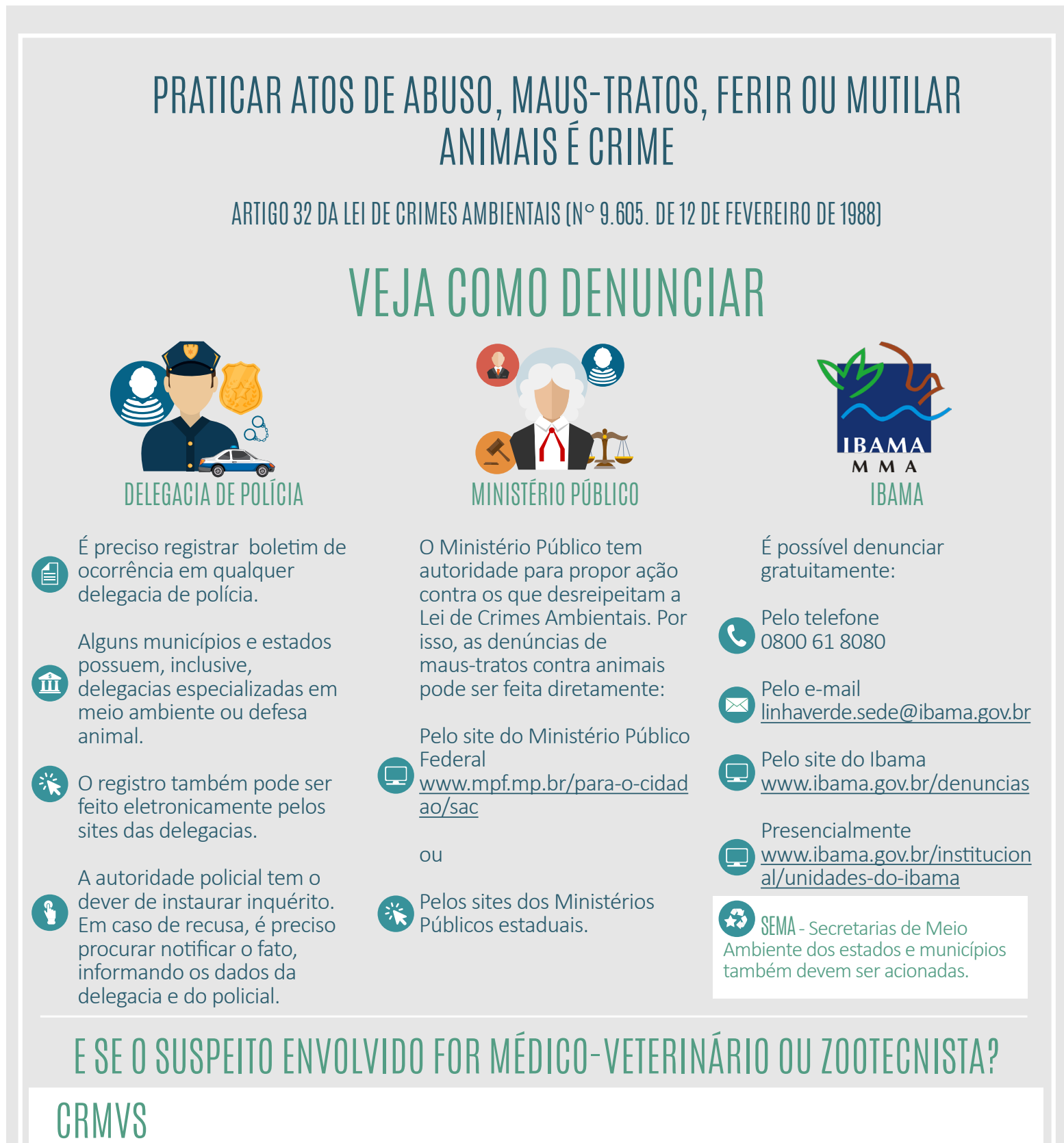

Após a denúncia nos órgãos competentes, descritos acima, maus-tratos praticados por médicos-veterinários ou zootecnistas também devem ser denunciados aos Conselhos Regionais de Medicina Veterinária (CRMVs).

Acesse os contatos:

\section{Portal.cFmv.GOv.br/CONSELhos-reglonals}

Os conselhos regionais são responsáveis por apurar os fatos e fiscalizar o exercício legal da profissão nos estados.

Após apuração, se constatados os maus-tratos, o médico-veterinário responderá processo ético-profissional, que será julgado em primeira instância pelos CRMVs.

\section{\CFMV}

Ao Conselho Federal de Medicina Veterinária (CFMV) só cabe julgar os processos disciplinares em segunda instância, a partir dos recursos interpostos contra decisões proferidas pelos CRMVs.

T Fonte: CFMV (2018). 


\section{Considerações Finais}

Os animais não têm capacidade de lutar por seus direitos, cabe então ao homem auxiliá-los nessa luta, seja criando uma lei específica para combater a zoofilia no Brasil, seja enquadrando este delito como estupro de vulnerável, por meio da Lei 12.015 (BRASIL, 2009), que diz respeito à fragilidade ou incapacidade, pois inexiste vulnerabilidade maior que a de um animal, que é privado de sua liberdade de consentir.

A omissão da sociedade e a falta de diálogos sobre o assunto expõem diversos adolescentes, principalmente de zonas rurais, à contaminação por várias doenças sexualmente transmissíveis, decorrentes de relações sexuais com animais. Há ainda a preocupação com o câncer de pênis, outras doenças e zoonoses que também podem ocorrer nos praticantes de zoofilia.

Uma sociedade apenas evolui quando os seus preceitos éticos evoluem e quando todos os seres vivos que a constituem são respeitados. Usar outro ser vivo para o bel prazer é extremamente cruel, egoísta e contrário aos anseios do presente (PRÓTON, 2017).

A zoofilia implicitamente se enquadra na prática de abusos e maus-tratos, mas não existe nenhuma legislação específica para tal, assim como também não há essa tipificação no atual Código Penal Brasileiro, o que permite a continuidade dessa prática culturalmente errônea, silenciosa e negligenciada. Aos poucos a humanidade tem percebido a brutalidade imposta aos animais e a necessidade de outorgar direitos a cada um deles, não como espécie e sim como indivíduo.

A zoofilia é um assunto velado e, consequentemente, também negligenciado num momento em que tanto se fala e se combate os maus-tratos aos animais, ela passa despercebida, é pouco abordada pelos profissionais da Medicina Veterinária e autoridades policiais. Contudo, para o estabelecimento de mudanças cabe a esses profissionais relatarem e denunciarem as ocorrências, pois a partir delas é que a sociedade entenderá melhor o sofrimento desnecessário pelo qual passam os animais vítimas de zoofilia e, a partir daí, poderá ser estabelecido um tipo penal específico para a bestialidade, construindo uma sociedade mais justa e menos maléfica e violenta.

0 abuso sexual deve ser adicionado, em circunstâncias apropriadas, à lista de diagnósticos diferenciais para lesões do aparelho reprodutor masculino e feminino das diferentes espécies animais, devendo estar incluído nos manuais de obstetrícia e ginecologia veterinária.

A prática de zoofilia, além de ser, por analogia, uma forma de estupro, é também um indício de problemas psicológicos que devem ser devidamente tratados por um profissional competente.\&

\section{Referências}

ALMEIDA, M. L.; ALMEIDA L. P.; BRAGA, P. F. S. Aspectos psicológicos na interação homem-animal de estimação. In: ENCONTRO INTERNO, 9.; SEMINÁRIO DE INICIAÇÃO CIENTÍFICA, 13., 2009, Uberlândia

Anais [...] Uberlândia: Universidade Federal de Uberlândia, 2009.

BEETZ, A. M. Bestiality and zoophilia: associations with violence and sex offending. In: BEETZ, A. M.; PODBERSCEK, A. L. (ed.). Bestiality and zoophilia: sexual relations with animals. Indiana: Purdue University Press West Lafayette, 2005. p. 46-70.

BEIRNE, P. Rethinking bestiality: towards a concept of interspecies sexual assault. Theoretical Criminology, [s.I.], v. 1, n. 3, p. 317-340, 1997. DOl: https://doi.org/10.1177/1362480697001003003.

BIZAWU, K.; RAMOS, A. O. B. Zoofilia no Brasil: uma análise de casos concretos e a necessidade de incriminação legal. Revista Brasileira de Direito Animal, Salvador, v. 12, n. 1, p. 81-107, jan./abr. 2017. DOI: https://doi.org/10.9771/rbda.v12i24.22020. 
BRASIL. Lei no 14.064, de 29 de setembro de 2020. Altera a Lei no 9.605, de 12 de fevereiro de 1998, para aumentar as penas cominadas ao crime de maus-tratos aos animais quando for cão ou gato.

Diário Oficial da União, Poder Executivo, Brasília, DF, 30 set. 2020. Seção 1, p. 4.

BRASIL. Lei no 9.605, de 12 de fevereiro de 1998. Dispõe sobre as sanções penais e administrativas derivadas de condutas e atividades lesivas ao meio ambiente e dá outras providências. Disponível em: http://www.planalto.gov.br/ccivil_03/leis/L9605.htm. Acesso em: 6 out. 2018.

BRASIL. Lei no 12.015, de 07 de agosto de 2009. Altera o Título VI da Parte Especial do Decreto-Lei no 2.848 de 07 de dezembro de 1940 - Código Penal [...] que dispõe sobre os crimes hediondos. Disponível em: http://www.planalto.gov.br/ccivil_03/_Ato2007-2010/2009/Lei/L12015.htm. Acesso em: 6 out. 2018.

CONSELHO FEDERAL DE MEDICINA VETERINÁRIA - CFMV. Etapas e órgãos oficiais para denunciar maus-tratos aos animais. Disponível em: http://www3.cfmv.gov.br/portal/public/noticia/index/ id/5862/secao/6. Acesso em: 6 dez. 2021.

CONSELHO FEDERAL DE MEDICINA VETERINÁRIA - CFMV. Resolução CFMV no 1.236 de 26 de outubro de 2018. Define e caracteriza crueldade, abuso e maus-tratos [...] dispõe sobre a conduta de médicosveterinários e zootecnistas e dá outras providências. Diário Oficial da União, Poder Executivo, Brasília, DF, 29 out. 2018. Seção 1, p. 133.

DARAYA, V. Orangotangos são vítimas de prostituição na África. 2014. Disponível em: https://exame. abril.com.br/ciencia/orangotangos-sao-vitimas-de-prostituicao-na-asia/. Acesso em: 3 out. 2018.

DELABARY, B. F. Aspectos que influenciam os maus tratos contra animais no meio urbano. Revista

Eletrônica em Gestão, Educação e Tecnologia Ambiental, Panambi, v. 5, n. 5, p. 835-840, 2012. DOI: https://doi.org/10.5902/223611704245.

DICIONÁRIO PRIBERAM DA LÍNGUA PORTUGUESA 2008-2020. Disponível em: https://dicionario. priberam.org/bestialismo. Acesso em: 3 jun. 2020.

FLEMING, W. M.; JORY, B.; BURTON, D. L. Characteristics of juvenile offenders admitting to sexual activity with nonhuman animals. Society \& Animals, [s.I.], v. 10, p. 1, 2002. DOI: https://doi. org/10.1163/156853002760030860.

GRAVINATTI, M. L.; BIONDO, A. W.; GARCIA, R. C. M. A zoofilia é doença, abuso físico e crime contra os animais. Clínica Veterinária, São Paulo, v. 117, p. 124-127, 2015.

IBGE - INSTITUTO BRASILEIRO DE GEOGRAFIA E ESTATÍSTICA. População de animais de estimação no Brasil - 2013. Disponível em: http://www.agricultura.gov.br/assuntos/camaras-setoriais-tematicas/ documentos/camaras-tematicas/insumos-agropecuarios/anos-anteriores/ibge-populacao-deanimais-de-estimacao-no-brasil-2013-abinpet-79.pdf. Acesso em: 10 abr. 2019.

LOPES, Y. J. As parafilias e os transtornos parafílicos, uma perspectiva das variações sexuais normais e patológicas. 2017. Disponível em: https://www.psicologia.pt/artigos/ver artigo.php?asparafilias-e-os-transtornos-parafilicos-uma-perspectiva-das-variacoes-sexuais-normais-e-patologicas \&codigo=A1179\&area=D11B. Acesso em: 10 abr. 2019.

LUCENA, B. B.; ABDO, C. H. N. Transtorno parafílico: o que mudou com o Manual Diagnóstico e Estatístico de Transtornos Mentais 5a edição (DSM-5). Diagnóstico e Tratamento, [s.l.], v. 19, n. 2, p. 94-6, 2014. Disponível em: http://files.bvs.br/upload/S/1413-9979/2014/v19n2/a4147.pdf. Acesso em: 3 jun. 2020.

MARLET, E. F.; MAIORKA, P. C. Análise retrospectiva de casos de maus tratos contra cães e gatos na cidade de São Paulo. Brazilian Journal of Veterinary Research and Animal Science, São Paulo, v. 47, n. 5, p. 385-394, 2010. DOI: https://doi.org/10.11606/issn.1678-4456.bjvras.2010.26820. 
MILETSKI, H. Understanding bestiality and zoophilia. In: BEETZ, A. M.; PODBERSCEK, A. L. (ed.).

Bestiality and zoophilia: sexual relations with animals. Indiana: Purdue University Press West Lafayette, 2005. p. 59-60.

MUNRO, H. M. C.; THRUSFIELD, M. "Battered pets": sexual abuse. In: BEETZ, A. M.; PODBERSCEK, A. L. (ed.). Bestiality and zoophilia: sexual relations with animals. Indiana: Purdue University Press West Lafayette, 2005. p. 71-81.

OLIVEIRA, W. F. A zoofilia é tolerável? In: SEMINÁRIO INTERNACIONAL FAZENDO GÊNERO, 10., 2013, Florianópolis. Anais [...] Florianópolis: Universidade Federal de Santa Catarina, 2013.

PRÓTON, S. Zoofilia e o direito dos animais. Canal Ciências Criminais, dez. 2017. Disponível em: https://canalcienciascriminais.com.br/zoofilia-direitos-animais/. Acesso em: 3 out. 2018.

SANTANA, L. R.; OLIVEIRA, T. P. Guarda responsável e dignidade dos animais. Salvador: Universidade Federal da Bahia, 2004. 41 p.

SANTANA, L. J.; MARQUES, M. R. Maus tratos e crueldade contra animais nos centros de controle de zoonoses: aspectos jurídicos e legitimidade ativa do Ministério Público para proporção ação civil pública. A Tarde e Tribuna da Bahia, Salvador, 2010.

SINGER, P. Practical ethics. 2nd. ed. New York: Cambridge University Press, 1999.

UNESCO. Declaração Universal dos Direitos dos Animais. Proclamada em sessão realizada em Bruxelas, Bélgica, em 27 jan. 1978. Disponível em: https://wp.ufpel.edu.br/direitosdosanimais/ files/2018/10/DeclaracaoUniversaldosDireitosdosAnimaisBruxelas1978.pdf. Acesso em: 6 dez. 2021. WEIDNER, E. Sodomie und Sadismus als Tierschutzproblem. 1972. Dissertação (Doutorado) University of Giessen, Germany, 1972.

WILLIAMS, C. J.; WEINBERG, M. S. Zoophilia in men: a study of sexual interest in animals. Archives of Sexual Behaviors, [s.I.], v. 32, n. 6, p. 523-535, 2003. DOl: https://doi.org/10.1023/A:1026085410617.

ZEQUU, S. C. Sexo com animais dobra o risco de câncer de pênis, revela estudo. 0 Estado do Maranhão, São Luís, 18 out. 2011. Disponível em: https://imirante.com/oestadoma/online/18102011/pdf/c08. pdf. Acesso em: 3 out. 2018. 